\title{
PROBIÓTICO FÚNGICO PARA OVINOS CONFINADOS RECEBENDO DIETA DE ALTO GRÃO DE MILHO
}

\author{
Ronaildo Fabino Neto ${ }^{1}$ \\ Flávia Oliveira Abrão ${ }^{2}$ \\ Marcelo Marcondes de Godoy ${ }^{2}$ \\ Laís Gabrielly Freitas Lima ${ }^{3}$ \\ Flavio Geraldo Ferreira Castro ${ }^{4}$ \\ Eliane Sayuri Miyagi ${ }^{2}$ \\ Victor Vieira Santana Neto ${ }^{5}$ \\ Mônica Maria de Almeida Brainer ${ }^{2}$
}

\begin{abstract}
RESUMO
Objetivou-se avaliar fungos ruminais como potenciais probióticos em associação a dietas de alto grão no desempenho e rendimento de carcaça, e quadro de acidose em borregos Santa Inês/Dorper. Adotou-se fatorial 4x2 em DIC, sendo dois processamentos (grão moído ou inteiro) e quatro inoculantes (sem inóculos, com Rhizomucor spp., com Aspergillus terreus e com mistura dos dois fungos). Utilizou-se oito baias com cinco borregos/baia, durante 75 dias. Dietas com $85 \%$ de milho associadas à $15 \%$ de núcleo foram fornecidas ad libitum duas vezes ao dia, com inóculos aspergidos no arraçoamento. Realizou-se cinco coletas de amostras dos ingredientes das dietas e das sobras durante o ensaio para realização das análises centesimais. Pesou-se os animais quinzenalmente para avaliação dos índices de desempenho. Ao final do ensaio, na ocasião do abate, foram calculados os rendimentos de carcaça de cinco animais por tratamento. Os dados foram submetidos à ANOVA e as médias dos dados comparadas pelo teste de Tukey a $5 \%$. Não houve interação entre os fatores processamento e probióticos para as variáveis de desempenho $(\mathrm{P}>0.05)$, assim como, não houve efeito da adição dos probióticos sobre o desempenho dos ovinos alimentados com os diferentes tratamentos $(\mathrm{P}>0.05)$. Foi observado maior consumo de MS, MM, EE, FDN e CNF para os animais alimentados com milho grão inteiro $(\mathrm{MGI})(\mathrm{P}<0.05)$. Não houve diferença significativa $(\mathrm{P}>0.05)$ para o consumo de $\mathrm{MO}, \mathrm{PB}, \mathrm{GPMD}$, ingestão de alimento e nem para eficiência alimentar. $\mathrm{O}$ aumento da concentração dos fungos e a associação dos fatores na dieta não demonstrou ser eficaz.
\end{abstract}

Palavra-chave: borrego, carcaça, confinamento, desempenho, dieta sem volumoso.

\section{FUNGAL PROBIOTIC FOR FEEDLOT SHEEP RECEIVING HIGH GRAIN CORN DIET}

\begin{abstract}
The objective of this study was to evaluate ruminal fungi as potential probiotics in association with high-grain diets in carcass performance and yield, and acidosis in Santa Inês/Dorper lambs. A 4x2 factorial was adopted in CRD, with two processes (ground or whole grain) and four inoculants (without inoculants, with Rhizomucor spp., With Aspergillus terreus and with

\footnotetext{
${ }^{1}$ Doutorando no Programa de Pós-Graduação em Zootecnia da Universidade Federal de Goiás. *Correspondência: ronaildo.neto@ifgoiano.edu.br

${ }^{2}$ Docente do Instituto Federal Goiano Campus Ceres, flavia.abrao@ifgoiano.edu.br

${ }^{3}$ Doutoranda no Programa de Pós-Graduação em Ciência Animal UFG, laisgabrielly.lima@ hotmail.com

${ }^{4}$ Gerente de Produtos da Agrocria Comércio e Indústria Ltda, flavio.castro@ agrocria.com.br

${ }^{5}$ Discente em Zootecnia pelo Instituto Federal Goiano Campus Ceres victor.santanafmo@gmail.com
} 
a mixture of fungi). Eight stalls with five lambs/stall were used for 75 days. Diets with $85 \%$ corn plus $15 \%$ nucleus are provided twice a day, with inoculants sprayed at the time of food handling. Five collections of ingredients of the ingredients of the diets, diets and leftovers were carried out during the experiment. The animals were weighed every two weeks. At the end of the experiment, on slaughter, the carcass index of five animals/treatment was calculated. Data were submitted to ANOVA and the data averages compared by the Tukey test at $5 \%$. There was no interaction between the processing and probiotic factors for the performance variables $(\mathrm{P}>0.05)$, just as there was no effect of the addition of probiotics on the performance of the sheep fed with the different treatments $(\mathrm{P}>0.05)$. Higher consumption of DM, MM, EE, NDF and NFC was observed for animals fed with whole grain corn (MGI) $(\mathrm{P}<0.05)$. There was no significant difference $(\mathrm{P}>0.05)$ for the consumption of $\mathrm{OM}, \mathrm{CP}$, MDG, intake and for food efficiency. The increase in the concentration of fungi and the association of factors in the diet did not prove to be effective.

Keywords: carcass, feedlot,lamb, diet without bulky, performance.

\section{PROBIÓTICO FUNGAL PARA OVEJAS CONFINADAS QUE RECIBEN UNA DIETA DE MAÍZ DE GRANO ALTO}

\section{RESUMEN}

El objetivo fue evaluar los fungal ruminales como probióticos potenciales en asociación con dietas ricas en granos en el actuación y rendimiento de la canal y la acidosis en corderos Santa Inês/Dorper. Adoptó un diseño completamente aleatorizado en factorial 4x2, con dos procesos (granos de maíz molidos o integral) y cuatro inoculantes (sin inóculo, con Rhizomucor spp., con Aspergillus terreus y con una mezcla de los dos hongos). Durante 75 días se utilizaron ocho establos con cinco corderos/puesto. Las dietas con $85 \%$ de maíz asociado con $15 \%$ de núcleo granos se proporcionaron ad libitum dos veces al día, con inoculantes rociados sobre el alimento. Durante la prueba se realizaron cinco recoleccion es de muestras de los ingredientes de las dietas y sobras para realizar los análisis centesimales. Los animales se pesaron cada das semanas para evaluar los índices de rendimiento. Al final de la prueba, en el momento del sacrificio, se calcularon los rendimientos en canal de cinco animales por tratamiento. Los datos se sometieron a análisis de variación y las medias de los datos se compararon mediante la prueba de Tukey al 5\%. No hubo interacción entre los factores de procesamiento y probióticos para las variables de desempeño $(\mathrm{P}>0,05)$, así como tampoco hubo efecto de agregar los probióticos sobre el desempeño de las ovejas alimentadas con los diferentes tratamientos $(\mathrm{P}>0,05)$. Se observó un mayor consumo de MS, MM, EE, NDF y CNF para los animales alimentados con maíz integral (MGI) $(\mathrm{P}<0,05)$. No hubo diferencia significativa ( $\mathrm{P}$ $>$ 0,05) para el consumo de MO, PC, GMDP, ingesta de alimentos y tampoco para la eficiencia alimentaria. El aumento de la concentración de hongos y la asociación de factores en la dieta no resultó eficaz.

Palabras chaves: canal, feedlot, cordero, dieta sin volumen, rendimento.

\section{INTRODUÇÃO}

O uso de grãos inteiros associados a um núcleo peletizado, tem sido praticado por muitos pecuaristas, em especial para bovinos de corte confinados em terminação, com o objetivo de acelerar o ganho de peso médio diário e reduzir custos. Além de ser uma 
alternativa para a falta de forragem, reduzir o custo com mão-de-obra, máquinas e equipamentos, pode ainda reduzir o tempo de abate e melhorar o rendimento e padronização de carcaça (1-3).

Dieta de alto grão (DAG), tem sido utilizada em borregos confinados na fase final, demonstrando respostas mais eficientes quando comparados aos bovinos (4,5). Contudo, DAG causa muitas discussões devido aos problemas metabólicos que podem impactar diretamente os animais $(1,6,7)$, os deixando mais susceptíveis à outras doenças por reduzirem sua imunidade (8-10).

Para eliminar os problemas metabólicos decorrentes da DAG, aditivos nutricionais comerciais vêm sendo utilizados. Alguns desses aditivos, como os antibióticos por exemplo, são proibidos por deixarem resíduos nos produtos e subprodutos de origem animal (11). Desta forma, como tendência naturalista, o uso de aditivos naturais como os probióticos tem se mostrado uma alternativa eficiente e em ascensão para a pecuária moderna, justamente por não deixarem resíduos nos produtos e assegurarem uma maior confiança dos consumidores finais $(12,13)$. A maioria dos probióticos nutricionais utilizados são bacterianos, sendo pouco os probióticos fúngicos. Entretanto, ressalta-se que o potencial dos fungos filamentosos para bovinos em condições de pastejo tem sido evidenciados nos últimos anos (14-16).

Fungos podem romper as paredes lignificadas das forragens com seus rizoides, ramificando e melhorando sua ação e, abrindo caminho para a ação de outros microorganismos (16), aumentando a degradação ruminal e o desempenho animal. Poucos trabalhos relatados na literatura evidenciam ação fúngica sobre os grãos ofertados aos animais sob DAG. Acredita-se que o aumento na concentração dos fungos anaeróbios facultativos do rúmen possa romper a matriz proteica, facilitando a digestão intestinal dos nutrientes.

Dessa forma, objetivou-se com o presente estudo verificar o potencial dos fungos Aspergillus terreus e/ou Rhizomucor spp. como aditivos nutricionais em dietas de alto grão para melhoria no desempenho, rendimento de carcaça e quadro de acidose em borregos confinados em fase final.

\section{MATERIAL E MÉTODOS}

\section{Ensaio de desempenho}

O experimento foi conduzido no setor de ovinocultura do Instituto Federal GoianoCampus Ceres, localizado na Rodovia GO 154, km 3, Zona Rural, no município de CeresGO, coordenadas geográficas: latitude $15^{\circ} 21^{\prime} 00^{\prime}$ ' S e longitude $49^{\circ} 36^{\prime} 05^{\prime}$ ' W altitude de 542 $\mathrm{m}$ acima do nível do mar.

As instalações do confinamento foram cobertas com telhas de barro, pé direito de três metros e com piso em concreto. O período experimental do confinamento iniciou-se em 15 de setembro e terminou em 29 de novembro de 2017 com duração de 75 dias, sendo 15 dias destinados à adaptação e 60 dias para coleta de dados, sendo subdivididos em quatro períodos experimentais de 15 dias.

Os fungos utilizados nesta pesquisa foram obtidos por meio da coleta de fluído ruminal de ovinos em experimentos anteriores, os quais foram mantidos sob dieta de alto grão (milho, milheto e/ou sorgo). Os fungos foram cultivados pela técnica de microcultivo, identificados por morfotipologia $(17,18)$, repicados e caracterizados por microscopia eletrônica de varredura (MEV).

O projeto foi submetido à apreciação da Comissão de Ética de Uso de Animais (CEUA) do Instituto Federal Goiano, com aprovação em 20/09/2016 com número de protocolo 9356170616. 


\section{Delineamento experimental}

Inicialmente, todos os animais foram pesados, identificados através de um colar numerado e vermifugados. Foram utilizados 40 borregos $1 / 2$ sangue Santa Inês x Dorper (20 machos e 20 fêmeas), com peso vivo inicial de aproximadamente $35 \mathrm{~kg}( \pm 5,00 \mathrm{~kg})$ e, com idade média de oito meses (intervalo de idade de sete a nove meses). Os animais foram distribuídos aleatoriamente em oito baias coletivas com dimensões de 5 × $5 \mathrm{~m}$, sendo seis animais por baia (três machos e três fêmeas).

Os tratamentos experimentais consistiram em dois tipos de processamentos do grão de milho (inteiro e moído) e quatro tipos de inoculantes (controle: sem inóculo fúngico - TE; com Rhizomucor spp. - RZ; com Aspergillus terreus - AT e com mix dos dois fungos - MX).

Foi utilizado o delineamento inteiramente ao acaso em um arranjo fatorial 4x2. Esse arranjo permitiu realizar um estudo das interações entre os fatores e dos fatores isolados. Sendo assim, avaliou-se o efeito do processamento do grão (inteiro ou moído) na dieta para o desempenho animal, considerando as baias como unidade experimental, sendo então quatro baias para cada processamento. Contudo, foram realizadas análise estatística do fator probiótico para os dados de desempenho.

Ao final dos 75 dias de confinamento, foram abatidos cinco animais por baia para determinação do rendimento de carcaça. Na avaliação de rendimento de carcaça cada animal foi considerado como uma unidade experimental para a avaliação das interações entre os dois fatores (processamento x inoculantes). Contudo, também foi realizado a avaliação dos fatores isoladamente.

Todos os tratamentos foram compostos com dieta de $85 \%$ de milho (grão inteiro ou moído) e $15 \%$ de núcleo comercial, e os animais de cada baia receberam os seguintes tratamentos:

- MGI-TE: $85 \%$ de grão de milho inteiro e $15 \%$ do núcleo comercial na dieta; sem adição de fungos.

- MGM-TE: $85 \%$ de grão de milho moído e $15 \%$ do núcleo comercial na dieta; sem adição de fungos.

- MGI-RZ: $85 \%$ de grão de milho inteiro e $15 \%$ do núcleo comercial na dieta; com adição de Rhizomucor spp.

- MGM-RZ: $85 \%$ de grão de milho moído e $15 \%$ do núcleo comercial na dieta; com adição de Rhizomucor spp.

- MGI-AT: $85 \%$ de grão de milho inteiro e $15 \%$ do núcleo comercial na dieta; com adição de Aspergillus terreus.

- MGM-AT: $85 \%$ de grão de milho moído e $15 \%$ do núcleo comercial na dieta; com adição de Aspergillus terreus.

- MGI-MX: $85 \%$ de grão de milho inteiro e $15 \%$ do núcleo comercial na dieta; com adição do mix dos dois fungos.

- MGM-MX: $85 \%$ de grão de milho moído e $15 \%$ do núcleo comercial na dieta; com adição do mix dos dois fungos.

\section{Manejo de arraçoamento}


A adaptação dos animais foi realizada com a substituição gradativa da fonte de volumoso pela dieta total de grão (inteiro ou moído) misturado ao núcleo de acordo com os tratamentos e seguindo o protocolo escada descrito por Brown et al. Perdigão et al. e Barducci et al. $(6,7,19)$. Dessa forma, de acordo com o protocolo de adaptação o arraçoamento consistiu em: do $1^{\circ}$ ao $5^{\circ}$ dia: $60 \%$ volumoso (feno de Tifton 85: Cynodon spp.) na matéria natural e $40 \%$ dieta total; do $6^{\circ}$ ao $10^{\circ}$ dia: $50 \%$ volumoso e $50 \%$ dieta total; do $11^{\circ}$ dia ao $15^{\circ}$ dia: $15 \%$ volumoso e $85 \%$ dieta total; do $16^{\circ}$ dia em diante: $0 \%$ volumoso e $100 \%$ da dieta total.

Durante o período experimental a alimentação foi fornecida duas vezes ao dia, sendo às $7 \mathrm{~h}$ e $16 \mathrm{~h}$. Foi realizado o controle de consumo (pesando-se a dieta fornecida e as sobras de cocho diariamente), permitindo a sobra de $5 \%$ da dieta ofertada.

Os inóculos foram fornecidos na dieta no momento do arraçoamento por meio da aspersão com inclusão de aproximadamente $14 \times 10^{11}$ esporos por compartimento (bomba de plástico com capacidade para 50 litros, de $545 \mathrm{~mm}$ de altura por 320x400 mm de diâmetro, cortado ao meio) de cocho de alimentação (10 borrifadas por compartimento de cocho). Assim, como cada baia continha quatro compartimentos por cocho, foram aspergidos em solução líquida o total de $56 \times 10^{11}$ esporos por baia e aproximadamente $9,33 \times 10^{11}$ esporos por animal por dia, garantindo um maior acesso dos animais a uma concentração mais elevada dos microrganismos selecionados como possíveis potenciais probióticos.

\section{Análises de composição da dieta}

O núcleo peletizado $\left(\right.$ Engordin $^{\circledR}$ ) usado nas dietas foi moído separadamente e em seguida misturado ao milho moído nos tratamentos com grãos moídos. Já para os tratamentos com grãos inteiros foi fornecido o núcleo misturado como pellet inteiro. O Engordin ${ }^{\circledR}$ é um núcleo próprio para uso em dieta de alto grão, e segundo informações do fabricante, é composto por fósforo (6000 mg kg${ }^{-1}$ ), cálcio (mínimo de $\left.34 \mathrm{~g} \mathrm{~kg}^{-1}\right)$, extrato etéreo $\left(10 \mathrm{~g} \mathrm{~kg}^{-1}\right)$, fibra em detergente neutro (mínimo de $220 \mathrm{~g} \mathrm{~kg}^{-1}$ ), matéria mineral (mínimo $200 \mathrm{~g} \mathrm{~kg}^{-1}$ ), proteína bruta (mínimo $380 \mathrm{~g} \mathrm{~kg}^{-1}$ ), nitrogênio não proteico equiparado em proteína (mínimo $\left.116 \mathrm{~g} \mathrm{~kg}^{-1}\right)$, cobalto $\left(5 \mathrm{mg} \mathrm{kg}^{-1}\right)$, cobre $\left(175 \mathrm{mg} \mathrm{kg}^{-1}\right)$, cromo $\left(1.4 \mathrm{mg} \mathrm{kg}^{-1}\right)$, enxofre $(4.500 \mathrm{mg}$ $\mathrm{kg}^{-1}$ ), iodo $\left(5 \mathrm{mg} \mathrm{kg}^{-1}\right)$, manganês $\left(180 \mathrm{mg} \mathrm{kg}^{-1}\right)$, magnésio $\left(3.000 \mathrm{mg} \mathrm{kg}^{-1}\right.$ ), sódio (mínimo $9700 \mathrm{mg} \mathrm{kg}^{-1}$ ), potássio (15 $\mathrm{g} \mathrm{kg}^{-1}$ ), zinco (mínimo $\left.420 \mathrm{mg} \mathrm{kg}^{-1}\right)$, iodo $\left(5 \mathrm{mg} \mathrm{kg}{ }^{-1}\right)$, virginiamicina $\left(150 \mathrm{mg} \mathrm{kg}^{-1}\right)$, monensina $\left(150 \mathrm{mg} \mathrm{kg}^{-1}\right)$, vitaminas A (21.000 U.I kg-1 $)$, D (3.600 U.I. kg ${ }^{-1}$ ) e E (135 U. I. kg-1) e outros minerais essenciais com umidade de $120 \mathrm{~g} \mathrm{~kg}^{-1}$ (90\% de MS).

Para determinação da composição bromatológica das dietas dos tratamentos, foram realizadas análises da matéria seca $(\mathrm{MS})$, proteína bruta $(\mathrm{PB})$, extrato etéreo $(\mathrm{EE})$, fibra em detergente neutro (FDN), fibra em detergente ácido (FDA) e carboidrato não fibroso (CNF), conforme a metodologia descrita por Detmann et al. (20). Os ingredientes da ração (agrupadas por tratamento) foram secas a $60^{\circ} \mathrm{C}$ por $72 \mathrm{~h}$, moídas em um moinho Willey em peneira de 2 mm (modelo padrão 4; Arthur M. Thomas, Filadélfia, PA). Foram realizadas as análises para MS (método INCT-CA G-003/1), cinzas (método INCT-CA M-001/1), PB (método INCTCA N-001/1) e EE (método INCT-CA G-004/1). As concentrações de FDA e FDN com a inclusão de $\alpha$-amilase utilizando autoclave (método INCT-CA F-004/1 e INCT-CA F-002/1, respectivamente) (20) sendo o CNF estimado pela equação $\mathrm{CNF}=100-\mathrm{MM}-\mathrm{PB}-\mathrm{EE}-$ FDN (21).

$\mathrm{Na}$ Tabela 1 estão relacionadas a composição química do alimento (milho) usado nas dietas experimentais como também a composição das dietas experimentais à base de milho 
grão inteiro (MGI) e milho grão moído (MGM), com base na matéria natural fornecida aos animais confinados.

Tabela 1. Composição química do milho e dietas experimentais $(\mathrm{g} / \mathrm{kg})$ na matéria natural

\begin{tabular}{lccc}
\hline Componentes $(\mathrm{g} / \mathrm{kg})$ & Milho & $\begin{array}{c}\text { Dieta milho grão } \\
\text { inteiro }\end{array}$ & $\begin{array}{c}\text { Dieta milho grão } \\
\text { moído }\end{array}$ \\
\hline Matéria seca & 925,98 & 890,95 & 889,20 \\
Matéria mineral & 10,88 & 36,50 & 39,45 \\
Matéria orgânica & 989,12 & 963,50 & 960,55 \\
Fibra em detergente neutro & 323,18 & 250,24 & 183,63 \\
Fibra em detergente ácido & 242,73 & 31,57 & 38,10 \\
Extrato etéreo & 11,00 & 27,00 & 23,50 \\
Carboidrato não fibroso & 572,59 & 562,94 & 620,23 \\
Proteína bruta & 82,35 & 123,33 & 124,09 \\
\hline
\end{tabular}

${ }^{4}$ Carboidratos não fibrosos (CNF) calculados com base no FDN (CNF = $\left.100-\mathrm{MM}-\mathrm{PB}-\mathrm{EE}-\mathrm{FDN}\right)$.

\section{Desempenho animal e rendimento de carcaça}

Foram realizadas pesagens dos animais ao final de cada período, totalizando cinco pesagens. Antes da pesagem, os animais foram mantidos em jejum com acesso direto à água durante 12 horas. As rações e sobras de cocho foram pesadas diariamente e coletadas amostras a cada período (cinco amostragem), para o registro do consumo e análise centesimal de ração.

A partir dos dados das pesagens foram determinados o peso inicial (PI), peso final (PF), ganho de peso total (GPT), ganho de peso médio diário (GPMD). A partir dos dados de pesagem das rações e sobras foi realizado os cálculos de consumos de MS, MM, MO, EE, PB, FDN e FDA. Para tanto, foi feita as análises de concentração dos nutrientes na ração fornecida e sobra, pelas metodologias descritas anteriormente. Em seguida, foram realizados os cálculos pela diferença do fornecido pela sobra com base na matéria seca.

Ao final do período de confinamento ( 75 dias), os animais foram novamente pesados e transportados para o abate no setor de Agroindústria do IF Goiano - Campus Ceres. O abate foi realizado por insensibilização elétrica com eletrodos e posterior sangria através do corte da veia jugular e artéria carótida. Foi adotado o manejo pré-abate com 12 horas de jejum e respeito às normas higiênica-sanitárias de bem-estar animal. Foram então determinados os dados de peso vivo ao abate (PVA), peso de carcaça quente (PCQ), peso de carcaça fria (PCF), rendimento de carcaça quente (RCQ) e rendimento de carcaça fria (RCF), de acordo com metodologia descrita por Cezar; Sousa (22), com adaptações de Oliveira et al.(23). Sendo assim, após o abate, sangria e evisceração foi determinado o PCQ para avaliação do RCQ (PCQ/PVA*100). Em seguida, as carcaças foram refrigeradas em câmara fria à $2^{\circ} \mathrm{C}$ por $24 \mathrm{~h}$ e posteriormente foram pesadas para a avaliação do RCF (PCF/PVA*100) $(4,24)$.

Após pesagem, as carcaças foram divididas ao meio e avaliadas o comprimento de carcaça e perna, circunferência de perna, profundidade de tórax, largura torácica e garupa segundo metodologia descrita por Xenofonte et al. (24). As carcaças foram seccionadas em sete regiões anatômicas para medida de peso das regiões do pescoço, costelas, lombo e serrote (25).

Para avaliação do efeito da dieta sem volumoso sobre a presença de acidose ruminal, foi realizada avaliação das características físicas visuais do rúmen, onde foi observada a coloração e descamação papilar. Para tanto, após o abate e extração do rúmen, o mesmo foi lavado em água corrente para avaliação visual de coloração e presença de descamação das papilas. 


\section{Análises estatísticas}

Após análise exploratória e descritiva dos dados, dados paramétricos foram submetidos à análise de variância (ANOVA) pelo pacote estatístico EASYANOVA do R (26), e as médias foram comparadas pelo teste de Tukey a $5 \%$ de probabilidade. Os modelos estatísticos usados para caracterização dos efeitos observados foram: Valores observado nas variáveis de desempenho: $\mathrm{Y}_{\mathrm{ijk}}=\mu+\mathrm{FP}_{\mathrm{i}}+\mathrm{FA}_{\mathrm{j}}+\mathrm{TF}_{(\mathrm{i}, \mathrm{j})}+\mathrm{PI}+\mathrm{PF}+\varepsilon_{\mathrm{ijk}}$; Valores observados nas variáveis de consumo: $\mathrm{Y}_{\mathrm{ijk}}=\mu+\mathrm{FP}_{\mathrm{i}}+\mathrm{FA}_{\mathrm{j}}+\mathrm{TF}_{(\mathrm{i}, \mathrm{j})}+\mathrm{DF}+\mathrm{SD}+\varepsilon_{\mathrm{ijk}}$; e Valores observados nas variáveis de biometria de carcaça: $\mathrm{Y}_{\mathrm{ijk}}=\mu++\mathrm{FP}_{\mathrm{i}}+\mathrm{FA}_{\mathrm{j}}+\mathrm{TF}_{(\mathrm{i}, \mathrm{j})}+\mathrm{PVA}+\mathrm{PC}_{(\mathrm{q}, \mathrm{f})}+\varepsilon_{\mathrm{ijk}}$. Em que: $\mathrm{Y}_{\mathrm{ijk}}=$ valor observações nos feitos; $\mu=$ efeito da média geral; $\mathrm{TF}_{(\mathrm{i}, \mathrm{j})}=$ interação entre os fatores processamentos $\times$ inoculantes; $\mathrm{FP}_{\mathrm{i}}=$ fator processamento (inteiro ou moído); $\mathrm{FA}_{\mathrm{j}}=$ fator probiótico (controle: sem inóculo fúngico - TE; com Rhizomucor spp. - RZ; com Aspergillus terreus - AT e com mix dos dois fungos - $\mathrm{MX}$ ); $\mathrm{PI}=$ peso inicial do animal; $\mathrm{PF}=$ peso final do animal; $\mathrm{DF}=$ peso da dieta fornecida; $\mathrm{SD}=$ peso da sobra de cocho; $\mathrm{PVA}=$ peso vivo ao abate; $\mathrm{PC}_{(\mathrm{q}, \mathrm{f})}=$ peso da carcaça $\left(\mathrm{q}=\right.$ quente ou $\mathrm{f}=$ fria); e $\varepsilon_{\mathrm{ijk}}=$ efeito aleatório do erro experimental;

\section{RESULTADOS E DISCUSSÃO}

Não houve efeito de interação entre os fatores processamento dos grãos e adição de probióticos para as variáveis de desempenho, assim como, não houve efeito da adição dos probióticos sobre o desempenho dos ovinos alimentados com os diferentes tratamentos. Deste modo, os dados foram analisados de forma independente, analisando os efeitos do processamento dos grãos, aos quais apresentaram diferenças significativas para algumas variáveis de consumo e biometria de carcaça.

Os consumos de matéria seca (MS), matéria mineral (MM), extrato etéreo (EE) e fibra em detergente neutro (FDN) foram maiores para os tratamentos com grão milho inteiro ( $\mathrm{P}<$ 0,01) (Tabela 2). Este resultado pode estar relacionado com a baixa disponibilidade dos nutrientes contidos no grão inteiro, o que dificulta o acesso da microbiota ruminal aos nutrientes necessários ao desenvolvimento microbiano levando ao aumento no consumo de alimento pelo hospedeiro. De acordo com Humer et al. (27) o processamento mecânico do grão de milho aumenta a disponibilidade de nutrientes que podem estar presos à matriz proteica, aumentando, portanto, a disponibilidade de proteína e de amido disponível para ser digerido no intestino delgado, e assim, reduzindo o consumo de alimento para os animais sob dieta de milho moído.

De acordo com Silva (28), existem dois principais mecanismos que regulam o consumo de alimentos pelos animais ruminantes. São eles: o mecanismo quimioestático, relacionado à dois fatores reguladores da saciedade, à concentração energética e proteica no metabolismo animal; e o outro é o mecanismo de distensão ruminal, que é acionado pelo limite máximo de expansão do rúmen. $\mathrm{O}$ ideal é que esses dois fatores sejam acionados ao mesmo tempo, assim o animal terá ingerido o máximo de alimento e atendido as suas exigências nutricionais.

A principal fonte energética dos ruminantes é procedente dos ácidos graxos de cadeia curta (AGCC), sendo esses resíduos provenientes da fermentação dos carboidratos realizado pela microbiota ruminal, sobretudo as bactérias (29). A concentração energética metabólica é um dos fatores de controle da saciedade pelo mecanismo quimioestático (28). Desta maneira, a baixa concentração desses carboidratos fermentativos no rúmen dos animais sob dieta de grão de milho inteiro, reduz a disponibilidade energética ruminal, devido à existência da matriz proteica. Além disso, o processo de degradação ruminal incompleta (baixa atividade de desnaturação da matriz proteica) do milho inteiro, contribui para o aumento de disponibilidade energética intestinal. Nesse sentido, os animais em dieta de grão de milho 
inteiro, tendem a aumentar o consumo, uma vez que o metabolismo energético intestinal é menos eficiente que o metabolismo energético ruminal.

A dieta de grão de milho inteiro reduz a disponibilidade de proteína microbiana, que é a principal fonte proteica para os ruminantes (30). Isso se deve à redução da população microbiana ruminal, principalmente bactérias, por consequência da baixa disponibilidade ruminal de carboidratos fermentativos, substrato necessário ao desenvolvimento dos microorganismos (31). Somado a este fator, a fermentação ruminal incompleta do grão de milho inteiro também contribui para o aumento da disponibilidade proteica no intestino, proveniente do milho inteiro, devido ao efeito de amolecimento da matriz proteica.

Tabela 2. Consumos de matéria seca e nutrientes por ovinos confinados recebendo dieta de alto grão inteiro ou moído, $\mathrm{kg} \mathrm{kg}^{-1}$

\begin{tabular}{|c|c|c|c|c|c|}
\hline \multirow{2}{*}{ Variáveis } & \multicolumn{2}{|c|}{ Processamento } & \multirow{2}{*}{$\frac{\text { P-valor }}{\text { Proc }^{3}}$} & \multirow{2}{*}{ EPM } & \multirow{2}{*}{$\mathrm{CV}(\%)$} \\
\hline & Inteiro & Moído & & & \\
\hline Consumo de Matéria Seca. $\mathrm{g} \mathrm{d}^{-1}$ & $1,219^{\mathrm{a}}$ & $1,009^{b}$ & $0,001^{* * * *}$ & 0,075 & 24,77 \\
\hline Consumo de Matéria Mineral. $\mathrm{kg} \mathrm{kg}^{-1}$ & $0,042^{\mathrm{a}}$ & $0,037^{\mathrm{b}}$ & $0,001^{* * *}$ & 0,001 & 28,26 \\
\hline Consumo de Matéria Orgânica. $\mathrm{kg} \mathrm{kg}^{-1}$ & 1,177 & 1,173 & 0,873 & 0,012 & 24,68 \\
\hline Consumo de Extrato Etéreo. $\mathrm{kg} \mathrm{kg}^{-1}$ & $0,034^{\mathrm{a}}$ & $0,029^{\mathrm{b}}$ & $0,001^{* * *}$ & 0,001 & 22,87 \\
\hline Consumo de Proteína Bruta. $\mathrm{kg} \mathrm{kg}^{-1}$ & 0,147 & 0,146 & 0,739 & 0,002 & 26,55 \\
\hline Consumo de Fibra em Detergente Neutro. $\mathrm{kg} \mathrm{kg}^{-1}$ & $0,299^{\mathrm{a}}$ & $0,207^{\mathrm{b}}$ & $0,001^{* * *}$ & 0,004 & 28,01 \\
\hline Consumo de Fibra em Detergente Ácido. $\mathrm{kg} \mathrm{kg}^{-1}$ & 0,047 & 0,047 & 0,712 & 0,001 & 24,02 \\
\hline Consumo de Carboidrato Não Fibroso. $\mathrm{kg} \mathrm{kg}^{-1}$ & $0,995^{\mathrm{a}}$ & $0,945^{\mathrm{b}}$ & $0,001^{* * *}$ & 0,001 & 10,130 \\
\hline Conversão Alimentar. $\mathrm{kg} \mathrm{kg}^{-1} / \mathrm{baia}$ & 5,344 & 4,8274 & 0,395 & 0,297 & 41,02 \\
\hline Eficiência Alimentar. $\mathrm{kg} \mathrm{kg}^{-1} / \mathrm{baia}$ & 0,221 & 0,230 & 0,706 & 0011 & 35,72 \\
\hline
\end{tabular}

${ }^{3}$ Proc: processamento, $\mathrm{CV}$ : coeficiente de variação, EPM: erro padrão médio. ${ }^{4}$ Médias na mesma linha que não apresenta um sobrescrito em comum, apresentam diferença significativa $(\mathrm{P}<0,05)$.

Os animais submetidos aos tratamentos com dieta de grão de milho inteiro apresentaram maior consumo médio diário de matéria seca do que os animais sob dieta de grão moído, sendo $1,219 \mathrm{~kg} \mathrm{dia}^{-1}$ e 1,009 $\mathrm{kg} \mathrm{dia}^{-1}$, respectivamente $(\mathrm{P}<0,01)$ (Tabela 2). Esses achados podem justificar o maior consumo de FDN, MM e EE na dieta de MGI $(\mathrm{P}<0,04)$. Os maiores consumos relacionam-se com o fato dos nutrientes necessários para ativação da saciedade estarem presos na matriz proteica. Desta forma, os hormônios de saciedade não são mobilizados, fazendo com que o animal consuma mais alimento (28).

O maior consumo de MS pelos animais sob dieta de MGI pode justificar maior PVA, PCQ, PCF (P < 0,01) (Tabela 4). Bernardes et al. (32) avaliaram a terminação de cordeiros machos castrados sob dieta de alto grão de milho (concentração de 72,83 \% da MS), de arroz com casca $(69,95 \%$ da MS), de aveia preta (81,60 da MS) e aveia branca (77,89\% da MS), ambos associados a um núcleo mineral (15\% da MS). Os autores observaram que os animais submetidos à dieta com grão de milho apresentaram maior consumo de MS, MO, PB, carboidratos totais e de NDT, contudo, apresentaram melhor escore de condição corporal, GPMD e conversão alimentar.

O fato do grão de milho ter menor concentração de fibra do que arroz com casca, aveia preta e aveia branca pode ter contribuído para o seu maior consumo, pois alimentos com maior teor de fibra tendem a ter um maior tempo de degradação ruminal (20). Sendo assim, o maior consumo de MS dos animais sob dieta com MGI no presente trabalho, pode ser justificado por conter menor teor de fibra. Alimentos fibrosos são mais difíceis de serem digeridos, o que reduz o consumo por proporcionarem efeito de enchimento do rúmen, sendo esse um outro fator que controla o consumo, justamente pela capacidade limite de distensão do rúmen (mecanismo de distensão ruminal) (28). 
As variáveis de desempenho (Tabela 3 ), assim como as variáveis relacionadas às características de carcaças como RCQ, RCF, peso do pescoço, pernil, paleta, serrote e das costelas, comprimento da carcaça (CC), largura torácica e garupa (LT e LG), profundidade de tórax (PT), comprimento de perna (CP), circunferência de perna (CirP), espessura da gordura subcutânea (EGS), marmoreio, pH de carcaça quente e fria (pHCQ e pHCQ) (Tabela 4), não apresentaram diferença significativa entre os tratamentos.

Tabela 3. Dados de desempenho ovinos alimentados com dieta de alto grão associado a diferentes a probiótico a base de fungos.

\begin{tabular}{lccccccccccc}
\hline \multirow{2}{*}{ Variáveis (kg) } & \multicolumn{3}{c}{ Processamento } & \multicolumn{4}{c}{ Probiótico } & \multicolumn{5}{c}{ P-valor } & \multirow{2}{*}{ EPM } & CV \\
\cline { 2 - 9 } & Inteiro & Moído & RZ & AT & TE & MX & Proc & Prob & & \\
\hline PI & 36,52 & 34,35 & 35,00 & 35,50 & 35,40 & 35,85 & 0,243 & 0,9903 & 0,855 & 17,92 \\
PF & 51,64 & 47,37 & 48,79 & 49,96 & 48,92 & 50,37 & 0,160 & 0,975 & 1,404 & 20,74 \\
GTP & 15,12 & 13,02 & 13,79 & 14,45 & 13,51 & 14,51 & 0,188 & 0,960 & 0,740 & 30,40 \\
GPMD & 0,270 & 0,232 & 0,246 & 0,258 & 0,241 & 0,259 & 0,186 & 0,959 & 0,013 & 29,37 \\
\hline
\end{tabular}

${ }^{2}$ EPM: erro padrão da média; CV: coeficiente de variação; Proc: processamento do grão; Prob: probióticos fúngicos; Rhizomucor spp. (RZ), Aspergillus terreus (AT), controle (TE) mistura dos dois fungos (MX). ${ }^{3}$ GPMD: ganho de peso médio diário; PI: peso inicial; PF: peso final; e GTP: ganho total de peso no período.

Contudo, PVA, PCQ, PCF, peso do lombo e fraldinha foram maiores $(\mathrm{P}<0,05)$ para dieta de grão inteiro (Tabela 4). Segundo Oliveira et al. (4), ao avaliarem o efeito do processamento do milho em dieta de alto grão para ovinos confinados, observaram que os animais em dieta MGI apresentaram maior conteúdo gástrico, o que justifica um maior PVA. Esse achado corrobora com os encontrados no presente estudo, pois o PVA foi maior para os animais sob dieta com grão de milho inteiro, sendo 50,33 kg para dieta de MGI e 46,51 kg para dieta de MGM (Tabela 4) $(\mathrm{P}<0,015)$. Isso poderia estar relacionado com o tempo de passagem da dieta de grão inteiro pelo trato gastrointestinal, e com isso, o tempo de jejum pode não ter sido o suficiente para esvaziamento do trato gastrointestinal (28). Contudo, a diferença encontrada também no PCQ e PCF (Tabela 4), sugere que os animais sob MGI apresentaram uma maior capacidade de deposição de nutrientes da dieta nas carcaças, garantindo maior peso quando comparados com animais sob MGM. Além disso, os animais sob MGI apresentaram maior CMS (Tabela 2).

Turgeon et al. (33), ao compararem a dieta de alto grão com dieta com volumoso para novilhos confinados em terminação, concluíram que a dieta de alto concentrado tende a diminuir o CMS e o GPMD, no entanto, melhora a eficiência alimentar e energética. Na presente pesquisa, no entanto, não houve interação significativa entres os fatores e nem efeito do fator processamento isoladamente sobre as variáveis eficiência alimentar e GPMD (Tabela $3)$.

$\mathrm{Na}$ avaliação de diferentes tipos de processamentos de grãos (inteiro ou moído, úmido ou seco) na dieta de cordeiros confinados, Oliveira et al. (4) concluíram que o processamento do grão não influenciou nas características da carcaça, porém o grão seco inteiro ou moído resulta em carcaças mais pesadas, quando comparado à dieta volumosa. No presente estudo, foi possível observar também que ovinos submetidos a dieta com grão de milho inteiro resultaram em carcaças mais pesadas, com PCQ: 27,50 kg e 25,20 kg para dieta de MGI e MGM respectivamente $(\mathrm{P}<0,01)$ (Tabela 4$)$.

Oliveira et al. (4), descrevem ainda que o uso de milho grão inteiro seco em dietas para ovinos, tornam-se economicamente mais convenientes por apresentarem menor custo no seu fornecimento aos animais. Além de reduzir tempo de confinamento, contribuindo para melhor escore de condição corporal. Esse achados reforçam as considerações de alguns autores ao afirmarem que dieta de alto grão reduz custo com mão-de-obra, como também o custo com 
máquinas e equipamentos, podendo ainda reduzir tempo de abate e contribuir com a melhoria nas características de qualidade da carcaça, além do peso, acabamento, marmoreio e padronização de carcaça $(2,32)$.

Durante o ensaio de desempenho não foi observado nenhum quadro de acidose nos animais. Assim como não foram observadas durante o abate descamações das papilas ruminais. Foi possível observar que os animais alimentados com grão inteiro apresentaram coloração das papilas ruminais mais escuras, enquanto que os animais com dieta de grão moído apresentaram coloração mais clara, o que sugere condições propicias para o desenvolvimento da acidose.

Tabela 4. Características relacionada à carcaça de ovinos alimentados com dieta de alto grão associados à diferentes probióticos a base de fungos.

\begin{tabular}{|c|c|c|c|c|c|c|c|c|c|c|}
\hline \multirow{2}{*}{ Variáveis } & \multicolumn{2}{|c|}{ Processamento } & \multicolumn{4}{|c|}{ Probiótico } & \multicolumn{2}{|c|}{ P-valor } & \multirow{2}{*}{ EPM } & \multirow{2}{*}{$\mathrm{CV}$} \\
\hline & Inteiro & Moído & RZ & AT & TE & MX & Proc & Prob & & \\
\hline PVA. Kg & $50,33^{\mathrm{a}}$ & $46,51^{b}$ & 46,58 & 49,63 & 47,68 & 49,8 & $0,015^{* *}$ & 0,360 & 1,078 & 9,94 \\
\hline PCQ. Kg & $27,50^{\mathrm{a}}$ & $25,20^{\mathrm{b}}$ & 25,31 & 27,25 & 25,68 & 27,16 & $0,010^{* *}$ & 0,257 & 0,644 & 27,00 \\
\hline PCF. Kg & $27,05^{\mathrm{a}}$ & $24,70^{\mathrm{b}}$ & 24,08 & 26,67 & 25,34 & 26,68 & $0,010^{* *}$ & 0,318 & 0,653 & 27,00 \\
\hline RCQ. \% & 54,87 & 54,19 & 54,42 & 54,95 & 54,1 & 54,65 & 0,212 & 0,717 & 0,292 & 27,00 \\
\hline RCF. \% & 53,92 & 53,09 & 53,31 & 53,74 & 53,29 & 53,67 & 0,143 & 0,907 & 0,285 & 3,26 \\
\hline Peso Pescoço. kg & 1,31 & 1,17 & 1,24 & 1,19 & 1,26 & 1,26 & 0,309 & 0,980 & 0,060 & 33,18 \\
\hline Peso Pernil. Kg & 3,50 & 3,36 & 3,28 & 3,54 & 3,40 & 3,50 & 0,442 & 0,717 & 0,083 & 16,36 \\
\hline Peso Paleta. Kg & 2,03 & 1,98 & 1,95 & 2,11 & 1,94 & 2,03 & 0,658 & 0,552 & 0,044 & 14,92 \\
\hline Peso Lombo. Kg & $1,11^{\mathrm{a}}$ & $0,94^{\mathrm{b}}$ & 1,00 & 1,01 & 0,99 & 1,09 & $0,011^{* *}$ & 0,611 & 0,032 & 18,89 \\
\hline Peso Serrote. Kg & 0,66 & 0,60 & 0,61 & 0,69 & 0,55 & 0,67 & 0,283 & 0,216 & 0,025 & 24,60 \\
\hline Peso Fraldinha. kg & $1,15^{\mathrm{a}}$ & $0,94^{\mathrm{b}}$ & 0,94 & 1,05 & 1,03 & 1,17 & $0,034^{*}$ & 0,447 & 0,049 & 29,36 \\
\hline Peso Cos $1^{\mathrm{a}}$ à $5^{\mathrm{a}} . \mathrm{kg}$ & 0,91 & 0,83 & 0,91 & 0,83 & 0,89 & 0,86 & 0,386 & 0,921 & 0,039 & 30,65 \\
\hline Peso Cos $6^{\mathrm{a}}$ à $13^{\circ} . \mathrm{kg}$ & 1,87 & 1,76 & 1,69 & 1,94 & 1,83 & 1,79 & 0,375 & 0,606 & 0,063 & 22,90 \\
\hline CC. $\mathrm{cm}$ & 68,00 & 67,18 & 66,57 & 68,23 & 67,75 & 67,80 & 0,605 & 0,893 & 0,721 & 7,36 \\
\hline LT. Cm & 18,57 & 18,12 & 17,70 & 19,30 & 18,05 & 18,35 & 0,468 & 0,306 & 0,297 & 10,56 \\
\hline LG. Cm & 17,67 & 17,07 & 16,60 & 18,00 & 17,30 & 17,6 & 0,377 & 0,514 & 0,319 & 12,18 \\
\hline PT. cm & 29,25 & 28,97 & 29,57 & 28,30 & 29,18 & 29,40 & 0,632 & 0,399 & 0,262 & 0,03 \\
\hline CP. Cm & 45,35 & 46,22 & 44,80 & 47,26 & 45,75 & 45,35 & 0,426 & 0,427 & 0,514 & 7,47 \\
\hline CirP. Cm & 47,35 & 47,07 & 45,85 & 47,65 & 47,55 & 47,80 & 0,746 & 0,333 & 0,424 & 5,64 \\
\hline EGS. Mm & 6,52 & 6,21 & 5,60 & 6,29 & 6,80 & 6,75 & 0,502 & 0,235 & 0,220 & 22,59 \\
\hline Marmoreio & 3,4 & 3,4 & 3,4 & 3,7 & 3,2 & 3,3 & 0,780 & 0,673 & 0,167 & 33,37 \\
\hline pHCQ & 6,55 & 6,53 & 6,46 & 6,53 & 6,55 & 6,62 & 0,866 & 0,839 & 0,059 & 6,27 \\
\hline $\mathrm{pHCF}$ & 5,81 & 5,88 & 5,86 & 5,87 & 5,78 & 5,88 & 0,577 & 0,941 & 0,061 & 7,24 \\
\hline
\end{tabular}

${ }^{2}$ PVA: peso vivo ao abate; PCQ: peso de carcaça quente; PCF: Peso de carcaça fria; RCQ: rendimento de carcaça quente; RCF: rendimento de carcaça fria; CC: comprimento da carcaça; LT: largura torácica; LG: largura de garupa; CP: comprimento de perna; CirP: circunferência de perna; PT: profundidade de tórax; Peso $\operatorname{Cos} 1^{\mathrm{a}}$ à $5^{\mathrm{a}}$ : peso do corte de costela da $1^{\mathrm{a}}$ a $5^{\mathrm{a}}$; Peso Cos. $6^{\mathrm{a}}$ às $13^{\mathrm{a}}$ : peso do corte de costela da $6^{\mathrm{a}}$ à $13^{\mathrm{a}}$ costela; EGS: espessura da gordura subcutânea; pHCQ: $\mathrm{pH}$ carcaça quente; $\mathrm{pHCF}$ : $\mathrm{pH}$ carcaça fria. ${ }^{3} \mathrm{EPM}$ : erro padrão da média; CV: coeficiente de variação; Proc: processamento do grão; Prob: probióticos fúngicos; Rhizomиcor spp. (RZ), Aspergillus terreus (AT), controle (TE) mistura dos dois fungos (MX). ${ }^{4}$ Médias na mesma linha que não apresenta um sobrescrito em comum, apresentam diferença significativa $(\mathrm{P}<0,05)$.

Abrão et al. (34), Vieira et al. (35) e Fabino Neto et al. (36), observaram que o rúmen de animais que apresentam o líquido ruminal mais claro e $\mathrm{pH}$ mais ácido sugerem um quadro de acidose. Contudo, apesar das papilas dos animais que receberam dieta de milho moído se apresentarem mais claras, os borregos não se encontraram em estado de acidose subclínica, pois não foram observadas ocorrências de lesões nas papilas. Provavelmente, tal fato pode estar relacionado ao uso do núcleo com aditivos (virginiamicina $=$ mínimo $150 \mathrm{mg} \mathrm{kg}^{-1}$ ) capazes de promover o equilíbrio do $\mathrm{pH}$ (32), o que contribuiu para a maior população de protozoários. 
O aumento da concentração do fungo Aspergillus terreus ou Rhizomucor spp. como probióticos não foram considerados eficazes, no presente estudo, que pode estar relacionado com o método de aplicação do inóculo, dosagem utilizada e/ou categoria animal estudada. Sugere-se a necessidade da realização de outros estudos a fim de evidenciarem outras concentrações e outros métodos de manejo para as aplicações dos probióticos a base de fungos ruminais para ovinos, sob dieta de alto concentrado.

\section{CONCLUSÃO}

O aumento da concentração dos probióticos fúngicos não foram consideradas eficazes. A dieta com milho grão inteiro foi melhor para garantir maior peso final dos animais e maior peso de carcaça quente e fria. Os animais sob as condições desse trabalho não apresentaram quadro de acidose.

\section{REFERÊNCIAS}

1. Beltrame JM, Ueno RK. Dieta $100 \%$ concentrado com grão de milho inteiro para terminação de bovinos de corte em confinamento [Internet]. Guarapuava: Universidade Tuituti do Paraná; 2011 [cited 2020 Sept 15]. Available from: https://tcconline.utp.br/wpcontent/uploads/2012/08/DIETA-100-POR-CENTO-CONCENTRADO-COM-GRAODE-MILHO-INTEIRO-PARA-TERMINACAO-DE-BOVINOS-DE-CORTE-EMCONFINAMENTO.pdf

2. Caetano M, Goulart RS, Rizzo PM, Silva SL, Drouillard JS, Leme PR, et al. Impact of flint corn processing method and dietary starch concentration on finishing performance of Nellore bulls. Anim Feed Sci Technol [Internet]. 2019 [cited 2020 Sept 15];251:166-75. Available from: https://linkinghub.elsevier.com/retrieve/pii/S0377840118302396

3. Venturini RS, Carvalho S, Pires CC, Pacheco PS, Pellegrin ACRS, Moro AB, et al. Consumo e desempenho de cordeiros e borregos alimentados com dietas de alto concentrado de milho ou sorgo. Arq Bras Med Vet Zootec [Internet]. 2016 [cited 2020 Sept 15];68(6):1638-46. Available

from: http://www.scielo.br/scielo.php?script=sci_arttext\&pid=S010209352016000601638\&lng=pt\&tlng=pt

4. Oliveira LS, Mazon MR, Carvalho RF, Pesce DMC, Silva SL, Nogueira Filho JCM, et al. Processamento do milho grão sobre desempenho e saúde ruminal de cordeiro. Cienc Rural [Internet]. 2015 [cited 2020 Sept 15];45(7):1292-8. Available from: http://www.scielo.br/scielo.php?script=sci_arttext\&pid=S0103$84782015000701292 \& \operatorname{lng}=$ pt\&tlng=pt

5. Paulino PVR, Oliveira TS, Gionbeli MP, Gallo SB. Dietas sem forragem para terminação de animais ruminantes. Rev Cient Prod Anim [Internet]. 2013 [cited 2020 Sept 15];15(2):161-72. Available from: http://www.bibliotekevirtual.org/index.php/2013-02-0703-02-35/2013-02-07-03-03-11/352-rcpa/v15n02/2877-v15n02a06.html

6. Barducci RS, Sarti LMN, Millen DD, Putarov TC, Franzói MCS, Ribeiro FA, et al. Restricted versus step-up dietary adaptation in Nellore bulls: Effects over periods of 9 and 
14 days on feedlot performance, feeding behavior and rumen morphometrics. Anim Feed Sci Technol. 2019;247:222-33. doi: https://doi.org/10.1016/j.anifeedsci.2018.11.012.

7. Perdigão A, Millen DD, Brichi ALC, Vicari DVF, Franzói MCS, Barducci RS, et al. Effects of restricted vs. step up dietary adaptation for 6 or 9 days on feedlot performance, feeding behaviour, ruminal and blood variables of Nellore cattle. J Anim Physiol Anim Nutr. 2018;102(1):224-34. doi: http://doi.wiley.com/10.1111/jpn.12681.

8. Abaker JA, Xu TL, Jin D, Chang GJ, Zhang K, Shen XZ. Lipopolysaccharide derived from the digestive tract provokes oxidative stress in the liver of dairy cows fed a high-grain diet. J Dairy Sci [Internet]. 2017 [cited 2020 Sept 15];100(1):666-78. Available from: https://www.sciencedirect.com/science/article/pii/S0022030216307901

9. Zhang RY, Jin W, Feng PF, Liu JH, Mao SY. High-grain diet feeding altered the composition and functions of the rumen bacterial community and caused the damage to the laminar tissues of goats. Animal [Internet]. 2018 [cited 2020 Sept 15];12(12):2511-20. Available

from: https://www.cambridge.org/core/product/identifier/S175173111800040X/type/journal_arti cle

10. Liu JH, Bian GR, Zhu WY, Mao SY. High-grain feeding causes strong shifts in ruminal epithelial bacterial community and expression of Toll-like receptor genes in goats. Front Microbiol. 2015 [cited 2020 Sept 15];6:167. Available from: http://journal.frontiersin.org/article/10.3389/fmicb.2017.02080/full

11. Uyeno Y, Shigemori S, Shimosato T. Effect of probiotics/prebiotics on cattle health and productivity. Microbes Environ [Internet]. 2015 [cited 2020 Sept 15];30(2):126-32. Available from: https://www.jstage.jst.go.jp/article/jsme2/30/2/30_ME14176/_article

12. Hill C, Guarner F, Reid G, Gibson GR, Merenstein DJ, Pot B, et al. The International Scientific Association for Probiotics and Prebiotics consensus statement on the scope and appropriate use of the term probiotic. Nat Rev Gastroenterol Hepatol [Internet]. 2014 [cited 2020 Sept 15];11(8):506-14. Available from: http://www.nature.com/articles/nrgastro.2014.66

13. Angelakis E. Weight gain by gut microbiota manipulation in productive animals. Microb Pathog. 2017;106:162-70. doi: http://dx.doi.org/10.1016/j.micpath.2016.11.002.

14. Abrão FO, Duarte ER, Pessoa MS, Santos VL, Freitas Júnior LF, Barros KO, et al. Notable fibrolytic enzyme production by Aspergillus spp. isolates from the gastrointestinal tract of beef cattle fed in lignified pastures. PLoS One [Internet]. 2017 [cited 2020 Sept 15];12(8):e0183628. Available from: https://dx.plos.org/10.1371/journal.pone.0183628

15. Abrão FO, Duarte ER, Pessoa MS, Santos VL, Rodriguez NM. Inocuidade micotoxicológica e viabilidade de Aspergillus spp. com potencial probiótico provenientes do trato digestório bovino. Arq Bras Med Vet Zootec [Internet]. 2018 [cited 2020 Sept 15];70(6):1833-9. Available from: http://www.scielo.br/scielo.php?script=sci_arttext\&pid=S010209352018000601833\&lng=pt\&tlng=pt 
16. Almeida PNM, Freitas CES, Abrão FO, Ribeiro ICO, Vieira EA, Geraseev LC, et al. Atividade celulolítica de fungos aerobios isolados do rúmen de bovinos leiteiros alimentados com forragens tropicais. Rev Caatinga [Internet]. 2014 [cited 2020 Sept 15];27(4):202-7. Available from: https://periodicos.ufersa.edu.br/index.php/caatinga/article/view/3317

17. Lacaz CS, Porto E, Martins JEC, Heins-Vaccari EM, Melo NT. Tratado de micologia médica. Rev Inst Med Trop Sao Paulo [Internet]. 2002 [cited 2020 Sept 15];44(5):297-8. Available from: http://www.scielo.br/scielo.php?script=sci_arttext\&pid=S0036$46652002000500013 \& \operatorname{lng}=\mathrm{en} \& \mathrm{nrm}=\mathrm{iso} \& \operatorname{tn} \mathrm{ln}=\mathrm{fr}$

18. Abrão FO, Duarte ER, Freitas CES, Vieira EA, Geraseev LC, Silva-Hughes AF, et al. Characterization of fungi from ruminal fluid of beef cattle with different ages and raised in tropical lignified pastures. Curr Microbiol [Internet]. 2014 [cited 2020 Sept 15];69(5):64959. Available from: http://link.springer.com/10.1007/s00284-014-0633-5

19. Brown MS, Ponce CH, Pulikanti R. Adaptation of beef cattle to high-concentrate diets: Performance and ruminal metabolism1. J Anim Sci [Internet]. 2006 [cited 2020 Sept 15];84 Suppl 13:E25-33. Available from: https://academic.oup.com/jas/article/84/suppl_13/E25/4776456

20. Detmann E, Souza M, Valadares Filho S, Queiroz A, Berchielli T, Saliba E, et al. Métodos para análise de alimentos. Visconde do Rio Branco: Suprema; 2012.

21. Mertens DR. Creating a system for meeting the fiber requirements of dairy cows. J Dairy Sci. 1997;80(7):1463-81. doi: http://dx.doi.org/10.3168/jds.S0022-0302(97)76075-2.

22. Cezar MF, Sousa WH. Carcaças ovinas e caprinas: obtenção avaliação classificação. Uberaba: Agropecuária Tropical; 2007. 232 p.

23. Oliveira LS, Mazon MR, Carvalho RF, Pesce DMC, Da Luz E Silva S, Gallo SB, et al. Effects of processing corn on the carcass traits and meat quality of feedlot lambs. Trop Anim Health Prod [Internet]. 2015 [cited 2020 Sept 15];47(5):883-7. Available from: http://link.springer.com/10.1007/s11250-015-0803-x

24. Xenofonte ARB, Carvalho FFR, Batista ÂMV, Medeiros GR. Características de carcaça de ovinos em crescimento alimentados com rações contendo farelo de babaçu. Rev Bras Zootec. 2009;38(2):392-8. doi: https://doi.org/10.1590/S1516-35982009000200024.

25. Colomer Rocher F, Morand-Fehr P, Kirton AH, Delfa Belenguer R, Sierra Alfranca I. Métodos normalizados para el estudio de los caracteres cuantitativos y cualitativos de los canales caprinas y ovinas [Internet]. Madrid: INIA; 1988 [cited 2020 Sept 15]. Available from: http://hdl.handle.net/10532/1424.

26. Arnhold E. Package in the $\mathrm{R}$ environment for analysis of variance and complementary analyses. Braz J Vet Res Anim Sci [Internet]. 2013 [cited 2020 Sept 15];50(6):488-92. Available from: https://pesquisa.bvsalud.org/portal/resource/pt/lil-789914 
27. Humer E, Zebeli Q. Grains in ruminant feeding and potentials to enhance their nutritive and health value by chemical processing. Anim Feed Sci Technol. 2017;226:133-51. doi: http://dx.doi.org/10.1016/j.anifeedsci.2017.02.005.

28. Silva JFC. Mecanismos reguladores de consumo. In: Berchielli TT, Pires AV, Oliveira SG. Nutrição de ruminantes. 2a ed. Jaboticabal: Funep; 2011. p. 61-82.

29. Kozloski GV. Bioquímica dos ruminantes. 3a ed. Santa Maria: Editora UFSM; 2016.

30. Valadares Filho SC, Silva LFC, Gionbelli MP, Rotta PP, Marcondes MI, Chizzotti ML, et al. Exigências nutricionais de zebuínos puros e cruzados: BR-CORTE [Internet]. 3a ed. Viçosa: UFV, DZO; 2016 [cited 2020 Sept 15]. Available from: http://www.brcorte.com.br/br/livro2016/br

31. Barchielli TT, Pires AV, Oliveira SG. Nutrição de ruminantes. 2a ed. Jaboticabal: Funep; 2011.

32. Bernardes GMC, Carvalho S, Pires CC, Motta JH, Teixeira WS, Borges LI, et al. Consumo, desempenho e análise econômica da alimentação de cordeiros terminados em confinamento com o uso de dietas de alto grão. Arq Bras Med Vet Zootec [Internet]. 2015 [cited 2020 Sept 15];67(6):1684-92. Available from: http://www.scielo.br/scielo.php?script=sci_arttext\&pid=S010209352015000601684\&lng=pt\&tlng=pt

33. Turgeon OA, Szasz JI, Koers WC, Davis MS, Vander Pol KJ. Manipulating grain processing method and roughage level to improve feed efficiency in feedlot cattle. $\mathbf{J}$ Anim Sci [Internet]. 2010 [cited 2020 Sept 15];88(1):284-95. Available from: http://academic.oup.com/jas/article/88/1/284/4740462

34. Abrão FO, Duarte ER, Carolina A, Nigri DA, Luiza M, Silva F, et al. Caracterização físico-química e microbiológica e população de fungos no conteúdo ruminal de novilhos de corte hígidos ou com acidose ruminal. Rev Bras Med Vet [Internet]. 2015 [cited 2020 Sept 15];37(1):7-14. Available from: http://rbmv.org/index.php/BJVM/article/view/345

35. Vieira EA, Abrão FO, Ribeiro ICO, Nigri ACA, Silva KF, Careli RT, et al. Bastonetes Gram-negativos aeróbios e anaeróbios facultativos no fluido ruminal de bovinos de corte alimentados em pastagem lignificada e em novilhos com acidose ruminal. Pesqui Vet Bras [Internet]. 2015 [cited 2020 Sept 15];35(9):811-6. Available from: http://www.scielo.br/scielo.php?script=sci_arttext\&pid=S0100-

736X2015000900811\&lng=pt\&tlng=pt

36. Fabino Neto R, Oliveira ARJ, Dijkstra D, Curcino LHB, Godoy MM, Castro FGF, et al. População fúngica ruminal em cordeiros com dietas de alto grão submetidas a diferentes processamentos. Zootec Trop [Internet]. 2017 [cited 2020 Sept 15];35(1-2):25-34. Available http://www.sian.inia.gob.ve/revistas_ci/ZootecniaTropical/zt3512/pdf/Neto.pdf

from:

Recebido em: 07/09/2020 Aceito em: 02/03/2020 